\title{
SUSTAINABILITY FACTORS INFLUENCING TOURISTS' DESTINATION CHOICE DURING THE COVID-19 PANDEMIC
}

\author{
Arthur Filipe de Araújo ${ }^{1}$, Maria Isabel Marques ${ }^{2}$, Maria Teresa Candeias ${ }^{3}$ \& Armando Luís Vieira ${ }^{4}$ \\ 1,2Lusofona University - TRIEE \\ ${ }^{3}$ Lusofona University \\ ${ }^{4}$ University of Aveiro - GOVCOPP \\ (p5706@mso365.ulp.pt, p3837@mso365.ulp.pt, p3118@ulp.pt, aluisvieira@ua.pt)
}

\begin{abstract}
As recent studies show, tourists increasingly favour hotels and other tourism businesses that adopt more sustainable practices. This trend has arguably been intensified during the COVID-19 pandemic. Indeed, due to the restrictions regarding crowded places and closed spaces, a lot of tourists have (re)discovered nature. In this context, the present study aims to analyse tourists' evaluation of sustainability criteria and willingness to pay for items when choosing a destination during the COVID-19 pandemic. To this end, previously validated scales for sustainability criteria and willingness to pay (for a sustainable destination) were tested, through a confirmatory approach, in the context of the COVID-19 pandemic. In this context, data was collected through a survey questionnaire $(n=567)$ with Portuguese tourists and subjected to a Confirmatory Factor Analysis (CFA). The findings show that the factors hold their dimensionality, convergent validity, and reliability in the context of Portuguese tourists travelling during the COVID-19 pandemic. Moreover, a newly proposed item, related to the importance given to the inclusion of local producers in the tourism industry's supply chain, was validated. The findings also show that, especially when it comes to willingness to pay, factors with a direct effect on tourists' experience are significantly more valued. Additionally, the results point to a slightly different outlook on sustainability criteria by Portuguese tourists, which is likely related to the context of the pandemic. Finally, the findings provide useful insights for destination managers aiming to attract tourists with a more sustainable behaviour.
\end{abstract}

KEYWORDS: Tourism sustainability, Sustainable destination, Sustainability criteria, Willingness to pay, Covid-19

\section{PURPOSE AND BACKGROUND}

As recent studies show, tourists increasingly favour hotels and other tourism businesses that adopt more sustainable practices. This trend has arguably been intensified during the COVID-19 pandemic. Indeed, due to the restrictions regarding crowded places and closed spaces, a lot of tourists have (re)discovered nature. Indeed, tourism in nature does not necessarily mean sustainable tourism.

However, tourism in natural areas has the potential of educating tourists about the need for preserving natural resources and adopting a more sustainable lifestyle. In this context, the present study aimed to analyse tourists' evaluation of sustainability criteria and willingness to pay items when choosing a destination during the COVID-19 pandemic.

\section{METHODOLOGY}

To achieve the present study's objective, data was collected through a survey questionnaire $(n=567)$ with Portuguese tourists. The questionnaire included 24 sustainability criteria for destination choice and 15 items of tourists' willingness to pay for sustainable practices. 
The items were operationalized though 7-point Likert scale questions, through which respondents were invited to demonstrate how much importance they attribute to each item. The data was subjected to a confirmatory approach based on factor solution achieved by a previous study (Aydın \& Alvarez, 2020).

\section{FINDINGS}

The findings show that the factors hold their dimensionality, convergent validity, and reliability in the context of Portuguese tourists travelling during the COVID-19 pandemic. Only one factor of sustainability criteria was excluded due to its negative effect on reliability.

Moreover, the proposition of a new item, related to the importance given to the inclusion of local producers in the tourism industry's supply chain, both on the sustainability criteria and willingness to pay items, was corroborated. The findings also show that, especially when it comes to willingness to pay, factors with a direct effect on tourists' experience are significantly more valued.

\section{CONCLUSION}

The findings show that Portuguese tourists have a different outlook on the analysed items, particularly the sustainability criteria, as they tend to attribute a very similar value to all items within the list. This might be explained by an inherently different attitude to sustainable tourism criteria, when compared to other nationalities or specific tourist segments.

Another possibility is that this undifferentiated evaluation is a result of the COVID-19 pandemic, which might have exacerbated the importance given to certain items, while obscuring that of other items.

\section{CONTRIBUTION/PRACTICAL IMPLICATIONS}

The present study shows that, in addition to previously tested items, tourists also value the inclusion of local producers in the tourism supply chain when choosing a destination, even during the COVID-19 pandemic.

Findings also suggest that tourists are more likely to to pay more for sustainable practices when they have an expected positive effect on their overall experience. In this context, tourism businesses are advised to prioritise local-based supply chains and market such initiatives in a way that highlights the benefits to guests' experiences, rather focusing exclusively on the enhancement of local quality of life and overall sustainability performance.

\section{REFERENCES}

Asmelash, A. G., \& Kumar, S. (2019). Assessing progress of tourism sustainability: Developing and validating sustainability indicators. Tourism Management, 71, 67-83. https://doi.org/10.1016/j. tourman.2018.09.020

Aydın, B., \& Alvarez, M. D. (2020). Understanding the tourists' perspective of sustainability in cultural tourist destinations. Sustainability, 12(21). https://doi.org/https://doi.org/10.3390/su12218846

Cucculelli, M., \& Goffi, G. (2016). Does sustainability enhance tourism destination competitiveness? Evidence from Italian Destinations of Excellence. Journal of Cleaner Production. https://doi. org/10.1016/j.jclepro.2014.12.069 